\title{
Analysis of Transformation Orientation of Undergraduate Education Management in the New Era
}

\author{
Zhu Shuang, Ma Jinhua \\ Suzhou Art \& Design Technology Institute
}

Keywords: new era; undergraduate education; transformation orientation

\begin{abstract}
Since the college entrance exam was resumed in 1978, the number of undergraduate in our country increases every year; the employment pressure of graduates is also increased. Through 40-year development, many problems have arisen in the development process in terms of improving the education management of undergraduates, which have been solved in a relatively comprehensive manner and have made certain progress. But it still requires greater improvement and innovation. The managerial staff require further reinforcement in terms of their specialized ability. It needs urgent reform in the current big environment where the education teaching is connected to the international community. The important work for the college education management is to find the new-type management mode so as to face the new social tendency and the new realistic challenges. This paper starts from the reality, combines with the current concrete conditions and finds some solutions and development orientations.
\end{abstract}

Since the 21st century, based on the implementation of university enrollment increase system in our country and the new establishment of multiple universities, more and more students can realize their dreams of going to the college. There are more and more undergraduates, who have become the main force in the current society, which has also posed severe challenge to the quality of the university education and produced many problems to be solved. Colleges and universities should not only teach the specialized knowledge to students, but also pose strict requirements for students' behavior quality and ideological quality. In this way, a batch of excellent undergraduates with the good sense of social responsibility, responsible attitude in work, positive ideas, self-discipline, self-respect and self-love can be cultivated.

\section{Status Quo of the Undergraduate Education Management Mode}

With the social progress and development and in the big environment of the high-speed circulation of the internet information, the college education also makes progress towards diversity and multiple aspects, which further proposes the higher and more comprehensive requirements for the undergraduate education management. The management difficulty is also enlarged gradually. The former management mode has been restricted in multiple aspects; it can no longer adapt to the demands of new situations and also needs the gradual innovation and change.

At present, in the student education work in universities, the relationship between teachers and students is still that of "managers" and "the managed". Some universities can still continue to use the former management mode and do not consider about the influence of the social progress and development in the new era on the body and mind of students. Teachers guide students through an oppressive education mode, so that students' ability of finding the problems, knowing about the problems and solving the problems in learning and life is not fully improved. They do lack the ability of independent thinking and research. Meanwhile, the influence of family, learning, employment and external temptation on the psychology of students is also tested. The number of students with the psychological issues also increases year by year.

\section{Necessity of the Transformation of Undergraduate Education Management Mode}

Only by strengthening the strict management of the Party and government offices of universities, 
building the good teaching atmosphere and constructing the highly professionalized education team in universities can it realize the smooth transformation of the undergraduate management work. The conversion of the undergraduate education management mode needs to be constantly expanded and innovated. While requiring professionalization, it should strengthen the learning of advanced teaching experience and teaching skills and conduct the professionalized construction of teaching. The teaching management is gradually transformed to the professionalized and technical orientation. It promotes the social development and educational system to reach perfection. It is the necessary result of the coexistence of teaching theories and practice. Only under the professionalized teaching management system can teachers use the more scientific and more humanistic teaching means to educate students, help improve the former bad teacher-student relationship and help students make for the correct road of life planning. Only the harmonious relationship between teachers and students is the premise and primary conditions for the education reform and development.

\subsection{Strengthen the communications and contact between teachers and students, promote the informationized teaching development}

Education managers of university students occupy the dominant position in teaching management. Only by deeply changing the thoughts of the university student managers can it effectively reform the education management mode. The previous students are passively managed in accepting management; managers play the functions of supervision and management education. Only by turning the function of university student managers from supervision education to guiding service can students be turned from passive management to initiative change. Set up the good teaching atmosphere and promote the transformation of the education management mode. Only changing the authority is far from enough. In the informationized age, to integrate the informationized teaching to the undergraduate education management mode is the inevitable choice for the development of the times. Informationized teaching can improve the teaching efficiency, promote the deepening of the teaching system, perfect the teaching system and play the promoting role for the undergraduate teaching management.

\subsection{Innovate the teaching management, promote the cultivation of the comprehensive quality of undergraduates}

Undergraduate education management should be based on students, innovate the teaching management thoughts, analyze and study the ideology, behavior momentum, knowledge and ability of undergraduates and then make the education management mode suitable for the development demand. The teacher is the guider of students and the guiding light of students. Management transformation starts from the teacher. Teachers change their thoughts, improve and exert their guiding roles, emancipate students' thoughts and ideas, arouse students' imagination and practical manipulation, and formulate the student-oriented teaching management mode.

In the rapid development of our country, as to the quality of university development, the role of the management work is very important at this time. A manager team with the complete teaching system, the advanced education ideas and understanding of the university education meaning should be constructed. The so-called manager professionalization means that the managers must decide to be devoted to the university education all their lives, master related professional knowledge and struggle by taking the university education as their own cause. The university management work requires long-term carefulness and responsibility. It requires the managers to work carefully and keep with the times. As it is said, "professional people do professional things". The professionalization of the university student managers can change the free and desultory learning attitude of contemporary undergraduates, make some students who aim at getting the diploma change their ideas, which will not influence the school style, will not reduce the learning enthusiasm of other students and make them devoted to their learning, get rid of their reliance on the family and realize independence. It can also strengthen teachers' teaching awareness, change the repression relationship between teachers and students, make teachers better cultivate the independent thinking ability of students rather than merely follow the command of teachers, so as to cultivate the academic atmosphere of schools, prevent schools from wasting teaching resources and 
fully use the teaching resources. Create the good school atmosphere, build up the excellent social atmosphere and inherit many traditional virtues of the Chinese nation. The target is to reform the teaching management mode. Seen from the current form, these reforms are the key of the work in the next stage.

\section{Transformation Method of Undergraduate Education Management}

Now that the transformation of the management work can gain so much, the transformation work should be put on the agenda soon, but any work needs to pay attention to the working method. This paper proposes several working methods and the matters needing attention in work.

\subsection{Change the employment mode of managers, improve the current training system}

The student managers mentioned not only include the cadres and counselors, but also include the professional teachers of the disciplines. The former employment system makes the working staff of the departments lack the crisis awareness, so that their professional level remains the same for multiple years. Therefore, with the arrival of the new age, we need to adopt the new manager employment method and post transfer mode, so as to improve the crisis awareness, form the benign competition and improve the professional level of managers. Complete the current examination means, such as setting up the monthly examination system and establishing the student evaluation feedback system. The training not only requires the professional technology of the training managers, but also combines the professional knowledge with the education theories. By targeting at the training of each department, depict a complete system, find problems in daily training and explore a set of complete training systems. After employment, the training work cannot be neglected either. Training that guarantees both quality and quantity should be done according to the current social form, which has deep influence for universities to encourage professionalization.

\subsection{Make efforts to construct the culture, cultivate the characteristics}

Importance attached to the cultural construction work helps strengthen the understanding of the important role played by the social construction. Inherit the traditional culture and carry forward the traditional culture. Truly embody the humanistic feelings of each university, retain and inherit the excellent tradition of each university. Prevent the teaching plan and the teaching system of each school from being repeated. Stick to the exclusive schooling idea of schools. Summarize experience, fully correct the past mistakes and carry forward the past achievements. Summarize the school styles and mottoes, impart them to students in daily teaching. Enable students not only to learn the professional skill knowledge, but also to get better ideological and cultural education.

\subsection{Implement the duties of the parties in an all-round way}

To fully implement the duties of the departments is the key point in work. Meanwhile, managers should fully consider various demands of students in learning and life in school. Managers should be turned into "servers" from "passive management" to "initiative service". The working contents of the university counselors and professional teachers should be combined to better carry out the student management work. Universities should set up the life service management station for daily life of students. Mentally and physically, it should provide the school infirmary and psychological health room. In terms of benefit and right, related aid points related to the law should be set up. Under this mode, the professional teachers should own the abundant knowledge of the professional courses, keep with the times and the era, keep updating their own knowledge bank. The life management service stations should guarantee to reduce the accident rate of students in learning and life and ensure the safety of students, teach the safety awareness to students, nip in the bud. In terms of psychological consultation, they should try to master the psychological course of each student in each stage, listen to students, provide the space for students to utter the problems they meet in learning and life and reduce students' pressure. The establishment of the legal aid points is to strengthen students' law protection awareness, help students solve the actual problems when they meet the legal dispute. Most importantly, counselors need to play the role of guiding and leading, 
help students solve problems in various aspects or find the solutions. They should become the good teachers of students, and the good friends of students in life.

\section{Conclusion}

At present, it is the good opportunity for our country to reform the university management system. We should seize the current opportunities, reform the current university management mode, get rid of the remaining problems caused by over administration, but it is a long way to go. The past management mode has been existing for a long time, so the road of reform is still long, which requires the participation of the national political system, the bold reform of the university student management system, the brave exploration of a large number of education workers and the careful summary. It also requires the universities to execute the policies, in order to create a better tomorrow for the Chinese universities, educate more undergraduates that strive for the construction of a new China. Undergraduates are the future of China. When teenagers become strong, the country will become strong. It is inevitable to get rid of the university student management administration and reform the management mode. At present, it is the intersection of reform. Only by bold innovation can it turn the universities into the cradle of cultivating talents and the warm bed of knowledge, so as to cultivate batches of excellent undergraduates who do not care about reputation and face, but only work for the national construction.

\section{References}

[1] Li Chunting; Chen Xiaohui; Problems and Solutions for University Student Management Work[J]; Journal of Chongqing Electric Power College; Periodical 4, 2008

[2] Li Xianling; Wu Haitao; Huang Hongwei; Difficulties and Solutions of University Student Work in the New Era[J]; The Guide of Science \& Education (First-third Journal); Periodical 8, 2010

[3] Du Yiqiang; Analysis of the Status Quo of University Student Management Work in the New Era[J]; Science \& Technology Information; Periodical 1, 2011

[4] Zhao Yinghua; Problems and Solutions for University Student Management Work in the New Situation[J]; Science \& Technology Information; Periodical 2, 2011

[5] Luo Zhizhe; Strategy Discussion of University Student Management Work[J]; Electronics World; Periodical 8, 2012

[6] She Jianfeng; Analysis of Transformation Orientation of Undergraduate Education Management Mode in the New Era[J]; Time Education; Periodical 15, 2013

[7] Xia Ruiwu; Peng Yu; Wang Jian; Jiang Hongwei; Thoughts about University Student Work in the New Situation[J]; China Construction Education; Periodical 2, 2006 